\title{
National and Regional Economic Growth with Fiscal Policies: Congested Public Goods and Endogenous Labor Supply of a Small-Open Economy
}

\author{
Wei-Bin Zhang \\ Ritsumeikan Asia Pacific University, 1-1 Jumonjibaru, Beppu-shi, Oita-ken, Japan \\ E-mail:wbz1@apu.ac.jp \\ Received August 12, 2010; revised September 16, 2010; accepted September 20, 2010
}

\begin{abstract}
The purpose of this study is to build a two-regional growth model with capital accumulation, endogenous time distribution between leisure and labor, and regional public goods with fiscal policies. We emphasize dynamic interactions among capital accumulation, externalities, supply of public good with different fiscal policies, congestion of public good, endogenous time, and economic geography. The economy consists of two regions and each region consists of the industrial sector and public sector. First, we develop the two-region growth model with public goods and fiscal policies. Second, we show how to find equilibrium values of the dynamic system. Then, we simulate model with specified parameter values. Finally, we carry out comparative statics analysis with regard to parameter changes in tax rates and congestion. Our comparative statics analysis provides some important insights. For instance, a main difference between the effects of increasing the two regions' tax rates on the output is that as region 1's (2's) tax rate on the industrial sector is increased, the national industrial output, national capital employed by the economy, and the national wealth are increased (reduced).
\end{abstract}

Keywords: Small-Open Economy, Interregional Economy, Capital Accumulation, Endogenous Leisure and Work Time, Fiscal Policies, Public Goods

\section{Introduction}

Interactions between economic growth, public good supply and environmental changes have caused a great attention from economists. Nevertheless, it is argued that a few theoretical models have been proposed to deal with these interactions within a interregional framework. As argued by [1,2], a main obstacle to properly modeling regional economic dynamics is that the traditional approaches to consumer behavior over time makes it analytically intractable to model interregional growth on the basis of profit- and utility-maximization. The productivity advantages of one region may be offset to some extent by the higher wages that must be paid in a system where people are free to choose where they work and live. Higher wages are often associated with some kinds of disamenities (such as noise, pollutants, and densely populated neighborhood) and high living costs. Labor and capital are easily mobile between regions in industrialized economies. As capital mobility becomes high and costs associated with capital movement among regions become low, it is reasonable to assume that capital movement tends to equalize marginal productivities of capital among regions within a national economy. But there are different principles for analyzing temporary equilibrium conditions for labor movement in a dynamic regional framework. In this study, we determine population distribution by the condition of equalizing utility level. This paper is a generalization of the two-region growth model proposed by Zhang [3]. This paper generalizes the previous model in introducing different fiscal policies and endogenous time distribution between leisure and work into the regional dynamic model. We also take account of congestion into consideration. This paper is organized as follows. Section 2 defines the two-region model with capital accumulation, endogenous time distribution, and public goods. Section 3 shows how to determine equilibrium of variables. Section 4 examines effects of changes in some parameters upon long-term national economic growth and economic geography. 
Section 5 concludes the study.

\section{The 2-Region Trade Model with Capital Accumulation}

This paper builds a dynamic one-commodity and two-region trade model to examine interdependence between regional trades and national growth with regional public goods and congestion. We analyze trade issues within the framework of a simple international macroeconomic growth model with perfect capital mobility. This model is influenced by the neoclassical trade theory with capital accumulation. Many one-commodity trade models with capital accumulation have been proposed, for instance, by [4-10]. It is assumed that the regions produce a homogenous commodity and public goods. It is assumed that there is only one (durable) good in the national economy under consideration. Households own assets of the economy and distribute their incomes to consume and save. Industrial sectors or firms use capital and labor. Exchanges take place in perfectly competitive markets. Industrial sectors sell their product to households or to other sectors and households sell their labor and assets to industrial sectors. Factor markets work well; factors are inelastically supplied and the available factors are fully utilized at every moment. Saving is undertaken only by households, which implies that all earnings of firms are distributed in the form of payments to factors of production. We omit the possibility of hoarding of output in the form of non-productive inventories held by households. All savings volunteered by households are absorbed by firms. We require saving and investment to be equal at any point of time.

The system consists of two regions, indexed by $j=1,2$. Each region has industrial and public sectors, indexed by $i$ and $p$, respectively. Perfect competition is assumed to prevail in good markets both within each region and between the regions, and commodity is traded without any barriers such as transport costs or tariffs. The labor markets are perfectly competitive within each region and between the regions. Let prices be measured in terms of the commodity and the price of the commodity be unity. We denote wage and interest rates by $w_{j}(t)$ and $r_{j}(t)$, respectively, in the $j$ th region. The interest rate is equal throughout the national economy, i.e., $r_{j}(t)=r^{*}$, where $r^{*}$ is the rate of interest fixed in the international economy. We assume a homogenous population, $\bar{N}$, in the economy. A person is free to choose his residential location within the country. We assume that any person chooses the same region where he works and lives. Each region has fixed land. Land quality, climates, and environment are homogenous within each region, but they may vary among the regions.
We neglect transportation cost of commodities between and within regions. As amenity and land are immobile, wage rates and land rent may vary between the regions. Let $\bar{N}_{j}(t)$ and $N_{j}(t)$ stand for respectively the population and (qualified) labor force of region $j$. We introduce $\tau_{i j}, \tau_{r j}$, and $\tau_{w j}$ to stand for, respectively, the fixed tax rates on the industrial output, interest income and wage income in region $j$. Let $K_{m j}(t)$ $N_{m j}(t)$, and $F_{m j}(t)$ stand for the capital stocks, (qualified) labor force employed by, and output level of region $j$ 's sector $m . m=i, p$.

\subsection{Behavior of Producers}

We assume that each firm chooses two productive factors, capital, $K_{j}(t)$, and labor, $N_{j}(t)$, at each point of time to maximize its profit, with the level of public goods in the region as given. The production functions are given by

$$
\begin{aligned}
& F_{i j}(t)=\Omega_{j}(t) K_{i j}^{\alpha_{i}}(t) N_{i j}^{\beta_{i}}(t), \\
& \alpha_{i}, \beta_{i} \geq 0, \quad \alpha_{i}+\beta_{i}=1, \quad j=1,2
\end{aligned}
$$

where $\Omega_{j}(t)$ is a function of externalities, public service and congestion. We specify $\Omega_{j}(t)$ as follows

$$
\Omega_{j}(t)=A_{i j} F_{p j}^{\theta_{p}} K_{i j}^{\theta_{e}}(t)\left(\frac{K_{p j}(t)}{K_{i j}(t)}\right)^{\theta_{c}}, A_{i j}, \theta_{p}, \theta_{e}, \theta_{c} \geq 0
$$

where $F_{p j}^{\theta_{p}}(t)$ measures the effect of public service on the region's productivity, $K_{i j}^{\theta_{e}}(t)$ the effect of externalities, and $\left(K_{p j}(t) / K_{i j}(t)\right)^{\theta_{c}}$ the effect of congestion of public goods. Similar to [11], we interpret that when $\theta_{e}=\theta_{c}=0$, there is no congestion and no externality. The nonrival and nonexcludable public service is available equally to each agent, independent of the usage of others. Obviously this is a limited case as most of public services are subject to some degree of congestion. We take account of congestion effects by the term, $\left(K_{p j}(t) / K_{i j}(t)\right)^{\theta_{c}}$, implying that for a fixed level of public capital, a rise in the private capital tends to reduce the efficiency of public services. There are different ways of describing congestion (see [12]). Here we neglect possible congestion effects due to the region's population and consumption activities.

Markets are competitive; thus labor and capital earn their marginal products, and firms earn zero profits. The rate of interest, $r^{*}$, and wage rates, $w_{j}(t)$, are determined by markets. Hence, for any individual firm $r^{*}$ and $w_{j}(t)$ are given at each point of time. According to the neoclassical growth theory as in the Solow model [1], the marginal conditions are given by

$$
r^{*}+\delta_{k}=\frac{\alpha_{i} \bar{\tau}_{i j} F_{i j}}{K_{i j}}, \quad w_{j}=\frac{\beta_{i} \bar{\tau}_{i j} F_{i j}}{N_{i j}}
$$


where $\delta_{k}$ is the depreciation rate of physical capital and $\bar{\tau}_{i j} \equiv 1-\tau_{i j}$.

\subsection{Behavior of Consumers}

Each worker may get income from land ownership, wealth ownership and wages. In order to define incomes, it is necessary to determine land ownership structure. It can be seen that land properties may be distributed in multiple ways under various institutions. This study assumes the absentee land ownership. Land is owned by absentee landlords who spend their land incomes outside the economic system. This study uses the approach to consumers' behavior proposed by Zhang in the early 1990s [see, 1,2]. Let $\bar{k}_{j}(t)$ stand for the per capita wealth in region $j$. Let $h$ stand for the level of human capital and $T_{j}(t)$ the work time in region $j$. Each consumer of region $j$ obtains income

$$
y_{j}(t)=\bar{\tau}_{r j} r^{*} \bar{k}_{j}(t)+\bar{\tau}_{w j} h T_{j}(t) w_{j}(t), \quad j=1,2
$$

from the interest payment, $\bar{\tau}_{r j} r^{*} \bar{k}_{j}$, and the wage payment, $\bar{\tau}_{w j} h T_{j} w_{j}$, where $\bar{\tau}_{r j} \equiv 1-\tau_{r j}$ and $\bar{\tau}_{w j} \equiv 1-\tau_{w j}$. The disposable income is given by $\hat{y}_{j}(t)=y_{j}(t)+\bar{k}_{j}(t)$. At each point of time, a consumer distributes the total available budget among housing, $l_{j}(t)$, saving, $s_{j}(t)$, consumption of goods, $c_{j}(t)$. The budget constraint is given by

$$
R_{j} l_{j}+c_{j}+s_{j}=\hat{y}_{j}=\bar{\tau}_{r j} r^{*} \bar{k}_{j}+\bar{\tau}_{w j} h T_{j} w_{j}+\bar{k}_{j}
$$

where $R_{j}(t)$ is land rent in region $j$. Let $T_{0}$ stand for the (fixed) available time for work and leisure. The time constraint is expressed by $T_{j}(t)+T_{h j}(t)=T_{0}$.

Substituting this function into the budget constraint yields

$$
\begin{aligned}
& R_{j} l_{j}+\bar{\tau}_{w j} h T_{h j} w_{j}+c_{j}+s_{j}=\bar{y}_{j} \\
& \equiv \bar{\tau}_{r j} r^{*} \bar{k}_{j}+\bar{\tau}_{w j} h T_{0} w_{j}+\bar{k}_{j}
\end{aligned}
$$

We assume that utility level that the consumers obtain is dependent on the lot size, $l_{j}(t)$, the leisure time, $T_{h j}(t)$, the consumption level of commodity, $c_{j}(t)$, and the saving, $s_{j}(t)$. The utility level of the consumer in region $j, U_{j}(t)$, is specified as follows

$$
\begin{gathered}
U_{j}(t)=\theta_{j}(t) F_{p j}^{v_{h}} \eta_{j}^{\eta_{h}}(t) T_{h j}^{\sigma_{h}}(t) c_{j}^{\xi_{h}}(t) s_{j}^{\lambda_{h}}(t), \\
v_{h}, \sigma_{h}, \eta_{h}, \xi_{h}, \lambda_{h}>0
\end{gathered}
$$

in which $v_{h}, \eta_{h}, \xi_{h}$, and $\lambda_{h}$ are a typical person's elasticity of utility with regard to lot size, commodity and savings in region $j$. We call $\eta_{h}, \xi_{h}$, and $\lambda_{h}$ propensities to consume lot size, to consume goods, and to hold wealth (save), respectively. We assume that households would like to have more public goods with the other things fixed, that is, $v_{h}>0$. In (5), $\theta_{j}(t)$ is called region $j$ 's amenity level. In this study, we specify $\theta_{j}$ by $\theta_{j}(t)=\bar{\theta}_{j} \bar{N}_{j}^{b}(t)$, where $\bar{\theta}_{j}(>0)$ and $b$ are parameters. We don't specify the sign of $b$ as the population may have either positive or negative effects on regional attractiveness.

Maximizing $U_{j}(t)$ subject to the budget constraints (4) yields

$$
\begin{aligned}
& l_{j}(t) R_{j}(t)=\eta \bar{y}_{j}(t), \quad \bar{\tau}_{w j} h T_{h j}(t) w_{j}(t)=\sigma \bar{y}_{j}(t), \\
& c_{j}(t)=\xi \bar{y}_{j}(t), \quad s_{j}(t)=\lambda \bar{y}_{j}(t)
\end{aligned}
$$

in which

$$
\begin{aligned}
& \eta \equiv \rho \eta_{h}, \quad \sigma \equiv \rho \sigma_{h}, \quad \xi \equiv \rho \xi_{h}, \lambda \equiv \rho \lambda_{h}, \\
& \rho=\frac{1}{\eta_{h}+\sigma_{h}+\xi_{h}+\lambda_{h}}
\end{aligned}
$$

According to the definitions of $s_{j}(t)$, the wealth accumulation of the representative person in region $j$ is given by

$$
\dot{\bar{k}}_{j}(t)=s_{j}(t)-\bar{k}_{j}(t)
$$

As households are assumed to be freely mobile between the regions, the utility level of people should be equal, irrespective of in which region they live, i.e., $U_{1}(t)=U_{2}(t)$. The public sector maximizes the level of public services by choosing capital, $K_{p j}(t)$, labor force, $N_{p j}(t)$, as follows

$$
F_{p j}(t)=A_{p j} K_{p j}^{\alpha_{0 p}}(t) N_{p j}^{\beta_{0 p}}(t), \alpha_{0 p}, \beta_{0 p}, A_{p j}>0
$$

Let $Y_{p j}(t)$ stand for government $j$ 's tax income. Then we have

$$
Y_{p j}(t)=\tau_{i j} F_{i j}(t)+\tau_{r j} r^{*} \bar{k}_{j}(t) \bar{N}_{j}(t)+\tau_{w j} w_{j}(t) N_{j}(t)(9)
$$

where $\tau_{i j} F_{i j}, \tau_{r j} r^{*} \bar{k}_{j} \bar{N}_{j}$ and $\tau_{w j} w_{j} N_{j}$ are respectively the tax incomes from the production sector's output, the households' interest payments and the households' wage incomes.

The public sector in region $j$ is faced with the following budget constraint

$$
w_{j}(t) N_{p j}(t)+\left(r^{*}+\delta_{k}\right) K_{p j}(t)=Y_{p j}(t)
$$

Maximization of public services under the budget constraint yields

$$
\left(r^{*}+\delta_{k}\right) K_{p j}=\alpha_{p} Y_{p j}, \quad w_{j} N_{p j}=\beta_{p} Y_{p j}
$$

in which

$$
\alpha_{p} \equiv \frac{\alpha_{0 p}}{\alpha_{0 p}+\beta_{0 p}}, \quad \beta_{p} \equiv \frac{\beta_{0 p}}{\alpha_{0 p}+\beta_{0 p}}
$$

The total capital stock employed by the economy, $K(t)$, is equal to the total capitals employed by all the regions. That is 


$$
K(t)=\sum_{j=1}^{2}\left\{K_{i j}(t)+K_{p j}(t)\right\}=\sum_{j=1}^{2} K_{j}(t)
$$

where $K_{j}(t) \equiv K_{i j}(t)+K_{p j}(t)$. The assumption that labor force and land are fully employed is represented by

$$
\sum_{j=1}^{2} \bar{N}_{j}(t)=\bar{N}, \quad l_{j}(t) \bar{N}_{j}(t)=L_{j}, \quad j=1,2
$$

where $L_{j}$ is the given (residential) area of region $j$. We also have

$$
N_{i j}(t)+N_{p j}(t)=N_{j}(t)=h T_{j}(t) \bar{N}_{j}(t)
$$

The total wealth of the national economy is the sum of the wealth owned by all the households

$$
\bar{K}(t)=\sum_{j=1}^{2} \bar{k}_{j}(t) \bar{N}_{j}(t)
$$

We introduce $B(t)$ as the value of the economy's net foreign assets at $t$. The income from the net foreign assets, $E(t)$, which may be either positive, zero, or negative, is equal to $r^{*} B(t)$. According to the definitions of the national wealth, the capital stocks employed by the economy and the net foreign assets, we have $\bar{K}(t)=K(t)+B(t)$. A country's current balance at time $t$ is the change in the value of its net claims over the rest of the world - the change in its net foreign assets. If $\dot{B}(t)>0$, the economy as a whole is lending (in this case we say that the current account balance is in surplus); if $\dot{B}(t)<0$, the economy as a whole is borrowing (the current account balance is in deficit); and if $\dot{B}(t)=0$, the economy as a whole is neither borrowing nor lending (the current account balance is in balance). We have thus built the model with endogenous capital accumulation and regional capital and labor distribution. We now examine spatial equilibrium and effects of changes in different conditions upon the economic geography.

\section{Economic Equilibrium}

As it is difficult to conduct dynamic analysis, we are only concerned with steady states. In equilibrium the change rates of all the variables are equal to zero. By (7), we have $s_{j}=\bar{k}_{j}$ at steady state. From this equation and $s_{j}=\lambda \bar{y}_{j}$, we have $\bar{y}_{j}=\bar{k}_{j} / \lambda$. From (2) and (11), we solve $K_{p j} / K_{i j}=\alpha N_{p j} / N_{i j}$, where $\alpha \equiv \alpha_{p} \beta_{i} / \alpha_{i} \beta_{p}$. From this equation, $N_{j}=N_{i j}+N_{p j}$ and $K_{j}=K_{i j}+$ $K_{p j}$, we solve

$$
\begin{aligned}
& N_{i j}=\frac{\alpha N_{j}}{\alpha+\tilde{k}_{j}}, N_{p j}=\frac{\tilde{k}_{j} N_{j}}{\alpha+\tilde{k}_{j}}, \\
& K_{i j}=\frac{K_{j}}{1+\tilde{k}_{j}}, \quad K_{p j}=\frac{\tilde{k}_{j} K_{j}}{1+\tilde{k}_{j}}
\end{aligned}
$$

where $\tilde{k}_{j} \equiv K_{p j} / K_{i j}$. From the definition of $\Omega_{j}(t)$, (8) and (16), we can express the production functions as follows

$$
F_{i j}=\frac{\bar{A}_{j} \tilde{k}_{j}^{\bar{\theta}} K_{j}^{\bar{\alpha}} N_{j}^{\bar{\beta}}}{\left(1+\tilde{k}_{j}\right)^{\bar{\alpha}}\left(\alpha+\tilde{k}_{j}\right)^{\bar{\beta}}}
$$

where

$$
\begin{aligned}
& \bar{\theta} \equiv \theta_{p 1} \alpha_{0 p}+\theta_{c 1}+\theta_{p 1} \beta_{0 p}, \quad \bar{\alpha} \equiv \alpha_{i}+\theta_{e 1}+\theta_{p 1} \alpha_{0 p}, \\
& \bar{\beta} \equiv \beta_{i}+\theta_{p 1} \beta_{0 p}, \quad \bar{A}_{j} \equiv A_{i j} A_{p j}^{\theta_{p 1}} \alpha^{\beta_{i}}
\end{aligned}
$$

From (1), (16) and (17), we have

$$
\begin{gathered}
r^{*}+\delta_{k}=\frac{\alpha_{i} \bar{\tau}_{i j} \bar{A}_{j} \tilde{k}_{j}^{\bar{\theta}} K_{j}^{\bar{\alpha}-1} N_{j}^{\bar{\beta}}}{\left(1+\tilde{k}_{j}\right)^{\bar{\alpha}-1}\left(\alpha+\tilde{k}_{j}\right)^{\bar{\beta}}}, \\
w_{j}=\frac{\left(r^{*}+\delta_{k}\right)\left(\alpha+\tilde{k}_{j}\right) \beta_{i} K_{j}}{\alpha \alpha_{i} N_{j}\left(1+\tilde{k}_{j}\right)}
\end{gathered}
$$

From the marginal conditions for capital in (18), we have $K_{2}=\Lambda_{K} K_{1}$, where

$$
\Lambda_{K} \equiv\left[\frac{\bar{\tau}_{i 1} \bar{A}_{1} \tilde{k}_{1}^{\bar{\theta}} N_{1}^{\bar{\beta}}\left(\alpha+\tilde{k}_{2}\right)^{\bar{\beta}}}{\bar{\tau}_{i 2} \bar{A}_{2} \tilde{k}_{2}^{\bar{\theta}} N_{2}^{\bar{\beta}}\left(\alpha+\tilde{k}_{1}\right)^{\bar{\beta}}}\right]^{1 /(\bar{\alpha}-1)} \frac{1+\tilde{k}_{2}}{1+\tilde{k}_{1}} .
$$

From the definition of $\bar{y}_{j}$ and $\bar{y}_{j}=\bar{k}_{j} / \lambda$, we get $w_{j}=\lambda_{j} \bar{k}_{j}$, where $\lambda_{j} \equiv\left(1 / \lambda-1-\bar{\tau}_{r j} r^{*}\right) / \bar{\tau}_{w j} h T_{0}$. From $w_{j}=\lambda_{j} \vec{k}_{j}$ and the marginal conditions in labor market in (18), we get

$$
\bar{k}_{j}=\frac{\beta_{i} \bar{\tau}_{i j} \bar{A}_{j} \tilde{k}_{j}^{\bar{\theta}} K_{j}^{\bar{\alpha}} N_{j}^{\bar{\beta}-1}}{\alpha \lambda_{j}\left(1+\tilde{k}_{j}\right)^{\bar{\alpha}}\left(\alpha+\tilde{k}_{j}\right)^{\bar{\beta}-1}}
$$

From $N_{j}=h T_{j} \bar{N}_{j}$ in (14) and $T_{j}+T_{h j}=T_{0}$, we have $\bar{N}_{j}=N_{j} / h\left(T_{0}-T_{h j}\right)$. From $T_{h j}=\sigma \bar{y}_{j} / w_{j} \bar{\tau}_{w j} h$, $\bar{y}_{j}=\bar{k}_{j} / \lambda$ and $w_{j}=\lambda_{j} k_{j}$, we get

$$
T_{h j}=\tilde{a}_{j} \equiv \frac{\sigma}{\lambda \lambda_{j} \bar{\tau}_{w j} h}
$$

We thus determined the time distribution. Inserting $T_{h j}=\sigma / \lambda \lambda_{j} \bar{\tau}_{w j} h$. in $\bar{N}_{j}=N_{j} / h\left(T_{0}-T_{h j}\right)$, we have $\bar{N}_{j}=a_{j} N_{j}$, where $a_{j} \equiv 1 /\left(h T_{0}-\sigma / \lambda \lambda_{j} \bar{\tau}_{w j}\right)$. Insert $l_{j}=L_{j} / a_{j} N_{j}, \quad c_{j}=\xi \bar{k}_{j} / \lambda$, and $s_{j}=\bar{k}_{j}$ in the utility function

$$
\begin{aligned}
& U_{j}=\frac{A_{p j}^{v_{h}} \bar{\theta}_{j} L_{j}^{\eta_{h}} \xi^{\xi_{h}} \tilde{a}_{j}^{\sigma_{h}} a_{j}^{b-\eta_{h}}}{\lambda^{\xi_{h}}} N_{j}^{b+v_{h} \beta_{0 p}-\eta_{h}} \\
& \tilde{k}_{j}^{v_{h} \alpha_{0 p}+v_{h} \beta_{0 p}}\left(\frac{K_{j}}{1+\tilde{k}_{j}}\right)^{v_{h} \alpha_{0 p}}\left(\frac{1}{\alpha+\tilde{k}_{j}}\right)^{v_{h} \beta_{0 p}} \bar{k}_{j}^{\xi_{h}+\lambda_{h}}
\end{aligned}
$$

From (19), (20) and $U_{1}=U_{2}$, we have $N_{2}=\Lambda_{N} N_{1}$, 
where

$$
\begin{aligned}
& \Lambda_{N}\left(\tilde{k}_{1}, \tilde{k}_{2}\right) \equiv \hat{\theta}\left(\frac{\alpha+\tilde{k}_{2}}{\alpha+\tilde{k}_{1}}\right)^{\left((\bar{\beta}-1) \xi_{0}+v_{h} \beta_{0 p}+\bar{\beta}\left(v_{h} \alpha_{0 p}+\bar{\alpha} \xi_{0}\right) /(\bar{\alpha}-1)\right) \bar{\eta}} \\
& \left(\frac{\tilde{k}_{1}}{\tilde{k}_{2}}\right)^{\left(v_{h} \alpha_{0 p}+v_{h} \beta_{0 p}+\bar{\theta} \xi_{0}-\bar{\theta}\left(v_{h} \alpha_{0 p}+\bar{\alpha} \xi_{0}\right) /(\bar{\alpha}-1)\right) \bar{\eta}} \text {, } \\
& \hat{\theta} \equiv\left[\frac{A_{p 1}^{v_{h}} \bar{\theta}_{1} L_{1}^{\eta_{h}} \tilde{a}_{1}^{\sigma_{h}} a_{1}^{b-\eta_{h}} \lambda_{2}^{\xi_{0}}}{A_{p 2}^{v_{h}} \bar{\theta}_{2} L_{2}^{\eta_{h}} \tilde{a}_{2}^{\sigma_{h}} a_{2}^{b-\eta_{h}} \lambda_{1}^{\xi_{0}}}\left(\frac{\bar{\tau}_{i 2} \bar{A}_{2}}{\bar{\tau}_{i 1} \bar{A}_{1}}\right)^{\left(v_{h} \alpha_{0 p}+\xi_{0}\right) /(\bar{\alpha}-1)}\right]^{\bar{\eta}}, \\
& \xi_{0} \equiv \xi_{h}+\lambda_{h}, \quad \bar{\eta} \equiv \\
& \frac{1}{b+v_{h} \beta_{0 p}-\eta_{h}+(\bar{\beta}-1) \xi_{0}+\left(v_{h} \alpha_{0 p}+\bar{\alpha} \xi_{0}\right) \bar{\beta} /(\bar{\alpha}-1)}
\end{aligned}
$$

From $\bar{N}_{1}+\bar{N}_{2}=\bar{N}, \bar{N}_{j}=a_{j} N_{j}$, and $N_{2}=\Lambda_{N} N_{1}$, we solve

$$
N_{1}=\frac{\bar{N}}{a_{1}+a_{2} \Lambda_{N}}, \quad N_{2}=\frac{\Lambda_{N} \bar{N}}{a_{1}+a_{2} \Lambda_{N}}
$$

We see that the labor distribution is uniquely determined as functions of $\tilde{k}_{1}$ and $\tilde{k}_{2}$. From the definition of $\Lambda_{K}$ and (21), we have

$$
\Lambda_{K}\left(\tilde{k}_{1}, \tilde{k}_{2}\right)=\left[\frac{\bar{\tau}_{i 1} \bar{A}_{1} \tilde{k}_{1}^{\bar{\theta}}\left(\alpha+\tilde{k}_{2}\right)^{\bar{\beta}}}{\bar{\tau}_{i 2} \bar{A}_{2} \tilde{k}_{2}^{\bar{\theta}} \Lambda_{N}^{\bar{\beta}}\left(\alpha+\tilde{k}_{1}\right)^{\bar{\beta}}}\right]^{1 /(\bar{\alpha}-1)} \frac{1+\tilde{k}_{2}}{1+\tilde{k}_{1}}
$$

From $K_{2}=\Lambda_{K} K_{1}$ and $K_{1}+K_{2}=K$, we have

$$
K_{1}=\frac{K}{1+\Lambda_{K}}, \quad K_{2}=\frac{\Lambda_{K} K}{1+\Lambda_{K}}
$$

We see that the capital distribution is uniquely determined as functions of $\tilde{k}_{1}$ and $\tilde{k}_{2}$.

From (11) and (16), we have

$$
K_{j}=\frac{\alpha_{p}\left(1+\tilde{k}_{j}\right)}{\left(r^{*}+\delta_{k}\right) \tilde{k}_{j}} Y_{p j}
$$

From the definition of $Y_{p j}$, we have

$$
Y_{p j}=\left(\frac{\alpha \tau_{i j} \lambda_{j}}{\beta_{i} \bar{\tau}_{i j}\left(\alpha+\tilde{k}_{j}\right)}+a_{j} \tau_{r j} r^{*}+\tau_{w j} \lambda_{j}\right) \bar{k}_{j} N_{j}
$$

where we use $F_{i j}=w_{j} N_{i j} / \beta_{i} \bar{\tau}_{i j}, \quad w_{j}=\lambda_{j} \bar{k}_{j}$, $\bar{N}_{j}=a_{j} N_{j}$, and the equation for $N_{i j}$ in (16). From the marginal conditions for labor markets in (18) and $w_{j}=\lambda_{j} \bar{k}_{j}$, we obtain

$$
\bar{k}_{j}=\frac{\left(r^{*}+\delta_{k}\right)\left(\alpha+\tilde{k}_{j}\right) \beta_{i} K_{j}}{\alpha \alpha_{i} \lambda_{j} N_{j}\left(1+\tilde{k}_{j}\right)}
$$

Substituting this equation and (23) and (25) into (24) yields

$$
\tilde{k}_{j}=\alpha\left(\frac{\tau_{i j} \lambda_{j}}{\beta_{i} \bar{\tau}_{i j}}+a_{j} \tau_{r j} r^{*}+\tau_{w j} \lambda_{j}\right)\left(\frac{\lambda_{j}}{\beta_{p}}-a_{j} \tau_{r j} r^{*}-\tau_{w j} \lambda_{j}\right)^{-1}
$$

The above equations determine the equilibrium values of $\tilde{k}_{j}$. The following lemma describes a procedure to determine the equilibrium values of all the variables.

\section{Lemma 1}

For a given rate of interest in the global market, the national economy has a unique equilibrium point. The equilibrium values of all the variables are given by the following procedure: $\tilde{k}_{j}(26) \rightarrow N_{j}$ by (21) $\rightarrow N_{i j}$ and $N_{p j}$ by $(16) \rightarrow \bar{N}_{j}=a_{j} N_{j} \rightarrow T_{h j}=\tilde{a}_{j} \quad \rightarrow$ $T_{h j}=T_{0}-T_{j} \rightarrow K_{j}$ by the marginal conditions for capital in (18) $\rightarrow K=K_{1}+K_{2} \rightarrow w_{j}$ by (18) $\rightarrow$ $K_{i j}$ and $K_{p j}$ by (16) $\rightarrow \bar{k}_{j}$ by (25) $\rightarrow Y_{p j}$ by (24) $\rightarrow \quad F_{i j}$ by (17) $\rightarrow F_{p j}$ by (8) $\rightarrow \bar{y}_{j}$ by (4) $\rightarrow$ $l_{j}=L_{j} / \bar{N}_{j} \rightarrow \bar{K} \quad$ by $(15) \rightarrow B=\bar{K}-K \quad \rightarrow$ $R_{j}=\eta \bar{y}_{j} / l_{j} \rightarrow c_{j}$ and $s_{j}$ by (6) $\rightarrow \quad C_{j}=c_{j} \bar{N}_{j}$ and $S_{j}=s_{j} \bar{N}_{j} \rightarrow U_{j}$ by (5).

Lemma 1 shows how to determine the values of all the variables in equilibrium. As the expressions are complicated, it is difficult to explicitly interpret the equilibrium conditions. For illustration, we specify the parameter values as follows

$$
\begin{gathered}
r^{*}=0.05, h=1, \alpha_{i}=0.3, \alpha_{0 p}=0.3, \beta_{0 p}=0.4, \\
\theta_{c}=0.05, \theta_{p}=0.04, \theta_{e}=0.03, A_{i 1}=1.2, A_{i 2}=1, \\
A_{p 1}=1.1, A_{p 2}=1, \quad b=-0.1, \bar{\theta}_{1}=3, \bar{\theta}_{2}=4, \\
\eta_{h}=0.09, \sigma_{h}=0.3, v_{h}=0.05, \delta_{k}=0.05, \xi_{h}=0.09, \\
\lambda_{h}=0.8, \quad N=10, L_{1}=3, L_{2}=4, \\
\tau_{i 1}=\tau_{r 1}=\tau_{w 1}=0.04, \tau_{i 2}=\tau_{r 2}=\tau_{w 2}=0.03 .
\end{gathered}
$$

The rate of interest is fixed at 5 percent in international market. The total population is 10 with human capital level being unit. The productivity parameter, $A_{i 1}$, is higher than region 2 , the productivity parameter of the public sector in region 1 is higher than that in region 2 . We consider that region 1 is technologically more advanced than region 2. Region 1' and 2' amenity parameters, $\bar{\theta}_{1}$ and $\bar{\theta}_{2}$, are different, the value in region 1 being lower than region 2. Region 1's land for housing is less than Region 2' land. The marginal propensity to consume public goods $v_{h}$, is lower than the propensity to consume the industrial goods, $\xi_{h}$, and the propensity to consume the lot size, $\lambda_{h}$. The tax rates on the output level, the income from wealth and wage income are the same within each region and the tax rates in region 1 are higher than the tax rates region 2 . The externality and congestion parameters, $\theta_{e}$ and $\theta_{c}$, are positive. It 
should be remarked that although the specified values are not based on empirical observations, the choice does not seem to be unrealistic. For instance, some empirical studies on the US economy demonstrate that the value of the parameter, $\alpha$, in the Cobb-Douglas production is approximately equal to 0.3 (for instance, [13]). With regard to the technological parameters, what are important in our interregional study are their relative values. The presumed productivity differences between the regions are not very large. This similarly holds for the specified differences in the amenity parameters between the regions.

Following the procedure in Lemma 1, we calculate the equilibrium values of all the variables. We list the simulation results as follows

$$
\begin{gathered}
F=4.64, K=14.79, \bar{K}=18.09, \quad B=3.30, \\
\bar{k}_{1}=2.07, \quad \bar{k}_{2}=1.55, \\
\left(\begin{array}{l}
N_{1} \\
N_{i 1} \\
N_{p 1}
\end{array}\right)=\left(\begin{array}{l}
1.58 \\
1.49 \\
0.10
\end{array}\right),\left(\begin{array}{l}
N_{2} \\
N_{i 2} \\
N_{p 2}
\end{array}\right)=\left(\begin{array}{l}
1.62 \\
1.55 \\
0.07
\end{array}\right),\left(\begin{array}{l}
K_{1} \\
K_{i 1} \\
K_{p 1}
\end{array}\right)=\left(\begin{array}{l}
8.46 \\
7.59 \\
0.86
\end{array}\right), \\
\left(\begin{array}{l}
K_{2} \\
K_{i 2} \\
K_{p 2}
\end{array}\right)=\left(\begin{array}{l}
6.34 \\
5.88 \\
0.49
\end{array}\right),\left(\begin{array}{l}
\bar{N}_{1} \\
T_{h 1} \\
T_{h 2}
\end{array}\right)=\left(\begin{array}{l}
4.93 \\
5.07 \\
0.68 \\
0.68
\end{array}\right),\left(\begin{array}{l}
F_{i 1} \\
F_{i 2} \\
F_{p 1} \\
F_{p 2}
\end{array}\right)=\left(\begin{array}{l}
2.64 \\
2.01 \\
0.41 \\
0.29
\end{array}\right), \\
\left(\begin{array}{l}
f_{i 1} \\
f_{i 2} \\
y_{p 1} \\
y_{p 2}
\end{array}\right)=\left(\begin{array}{l}
0.53 \\
0.40 \\
0.04 \\
0.02
\end{array}\right),\left(\begin{array}{l}
w_{1} \\
w_{2} \\
R_{1} \\
R_{2}
\end{array}\right)=\left(\begin{array}{l}
1.19 \\
0.88 \\
0.38 \\
0.22
\end{array}\right),\left(\begin{array}{l}
c_{1} \\
c_{2} \\
l_{1} \\
l_{2}
\end{array}\right)=\left(\begin{array}{l}
0.23 \\
0.17 \\
0.61 \\
0.80
\end{array}\right)
\end{gathered}
$$

In (28), the variables, $f_{i j}$ and $y_{p j}$, are respectively the output level per worker and the expenditure on public goods per resident in region $j$ defined as $f_{i j}=F_{i j} / N_{i j}, \quad y_{p j}=Y_{p j} / \bar{N}_{j}, \quad j=1,2$. Less than half of the national population but more than half of the total capital are located in region 1 . The per-capita levels of wealth and consumption and wage rate in region 1 are much higher than the corresponding variables in regions 2. The lot size of region 2 is larger than in region 1 . The consumption level per capita in region 1 is higher than in region 2. We see that although workers can earn more money in the advanced region than in the other region, they have to pay much higher rent for housing than the households in the other region. Expectably, the typical household in the advanced region consumes more goods and lives in a smaller house than the typical household in region 2 .

\section{Parameter Changes and Economic Geography}

It is important to ask questions such as how one region may affect the national economy as its technology or amenity is improved; or how the regional trade patterns may be affected as the propensity or the total population to save is increased. This section examines impact of changes in some parameters on the national economy and regional economic structures. As we have explicitly provided the procedure to simulate the motion, it is straightforward to make comparative analysis. First, we examine effects of change in the total productivity of region 2's industrial sector, $A_{i 2}$. We increase $A_{i 2}$ from 1 to 1.1 , keeping all the other parameter values as specified in (27). The simulation results are given in (29).

$$
\begin{gathered}
A_{i 2}: 1 \Rightarrow 1.1, \bar{\Delta} F=6.12, \bar{\Delta} K=5.99, \bar{\Delta} \bar{K}=6.19, \\
\bar{\Delta} B=7.05, \bar{\Delta} \bar{k}_{1}=-0.67, \bar{\Delta} \bar{k}_{2}=16.29, \\
\left(\begin{array}{c}
\bar{\Delta} N_{1} \\
\bar{\Delta} N_{i 1} \\
\bar{\Delta} N_{p 1}
\end{array}\right)=\left(\begin{array}{l}
-7.29 \\
-7.29 \\
-7.29
\end{array}\right),\left(\begin{array}{l}
\bar{\Delta} N_{2} \\
\bar{\Delta} N_{i 2} \\
\bar{\Delta} N_{p 2}
\end{array}\right)=\left(\begin{array}{l}
7.10 \\
7.10 \\
7.10
\end{array}\right),\left(\begin{array}{l}
\bar{\Delta} K_{1} \\
\bar{\Delta} K_{i 1} \\
\bar{\Delta} K_{p 1}
\end{array}\right)= \\
\left(\begin{array}{c}
-7.91 \\
-7.91 \\
-7.91
\end{array}\right),\left(\begin{array}{l}
\bar{\Delta} K_{2} \\
\bar{\Delta} K_{i 2} \\
\bar{\Delta} K_{p 2}
\end{array}\right)=\left(\begin{array}{l}
24.55 \\
24.55 \\
24.55
\end{array}\right),\left(\begin{array}{l}
\bar{\Delta} \bar{N}_{1} \\
\bar{\Delta} \bar{N}_{2} \\
\bar{\Delta} T_{h 1} \\
\bar{\Delta} T_{h 2}
\end{array}\right)=\left(\begin{array}{c}
-7.29 \\
7.10 \\
0 \\
0
\end{array}\right), \\
\left(\begin{array}{l}
\bar{\Delta} F_{i 1} \\
\bar{\Delta} F_{i 2} \\
\bar{\Delta} F_{p 1} \\
\bar{\Delta} F_{p 2}
\end{array}\right)=\left(\begin{array}{c}
-7.91 \\
24.55 \\
-5.35 \\
9.78
\end{array}\right),\left(\begin{array}{l}
\bar{\Delta} f_{i 1} \\
\bar{\Delta} f_{i 2} \\
\bar{\Delta} y_{p 1} \\
\bar{\Delta} y_{p 2}
\end{array}\right)=\left(\begin{array}{c}
-0.67 \\
16.29 \\
-0.67 \\
16.29
\end{array}\right), \\
\left(\begin{array}{l}
\bar{\Delta} w_{1} \\
\bar{\Delta} w_{2} \\
\bar{\Delta} R_{1} \\
\bar{\Delta} R_{2}
\end{array}\right)=\left(\begin{array}{c}
-0.67 \\
16.29 \\
-7.91 \\
24.55
\end{array}\right),\left(\begin{array}{l}
\bar{\Delta} c_{1} \\
\bar{\Delta} c_{2} \\
\bar{\Delta} l_{1} \\
\bar{\Delta} l_{2}
\end{array}\right)=\left(\begin{array}{c}
-0.67 \\
16.29 \\
7.87 \\
-6.63
\end{array}\right)
\end{gathered}
$$

where $\bar{\Delta}$ stands for the change rate of the variable in percentage due to changes in parameter value. As region 2's total productivity is increased, the national output, wealth and capital are increased. The trade balance is also improved. Hence, the national economy is improved as a whole. However, there are interregional differences in the impact due to the technological change. The region whose technology is improved attracts more households to the region. Region 2's rate is increased and the region becomes more attractive. People immigrate to region 2 from region 1 . The redistribution leads to fall in region 
1's land rent and rise a region 2's land rent. The region experiencing the technological change will increase its wage rate, while the wage rate in the other region falls. As the work time is not affected by the technological change, the changes in the national labor supply are due to regional reallocation of the households. As region 2 has more population, its lot size per household faces. We thus see that as region 2 increases its technology, at a new equilibrium its household will get more wage per work hour and increase the consumption and wealth, but the household will live in a smaller space.

In our dynamic system each region may conduct different fiscal policies. It is important to compare effects of change in different taxes upon the economic system. First, we increase the tax rate on region 1's output from 0.04 to 0.05 . The national output and wealth are increased. The capital stock employed by the country is increased. The trade balance is deteriorated. As region 1 's tax rate is increased, the expenditure on public good is increased (given all the other conditions). The improved infrastructure makes the region more attractive. The region's population is increased and productivity per work hour is increased. Region 1's wage rate and consumption are increased in association of rise in land rent; region 2's wage rate and consumption are reduced in association of fall in land rent.

$\tau_{i 1}: 0.04 \Rightarrow 0.05, \bar{\Delta} F=0.23, \bar{\Delta} K=0.46, \bar{\Delta} \bar{K}=0.12$, $\bar{\Delta} B=-1.41, \bar{\Delta} \bar{k}_{1}=0.10, \bar{\Delta} \bar{k}_{2}=-0.05$,

$$
\begin{gathered}
\left(\begin{array}{c}
\bar{\Delta} N_{1} \\
\bar{\Delta} N_{i 1} \\
\bar{\Delta} N_{p 1}
\end{array}\right)=\left(\begin{array}{c}
0.60 \\
-0.26 \\
13.89
\end{array}\right),\left(\begin{array}{l}
\bar{\Delta} N_{2} \\
\bar{\Delta} N_{i 2} \\
\bar{\Delta} N_{p 2}
\end{array}\right)=\left(\begin{array}{l}
-0.58 \\
-0.58 \\
-0.55
\end{array}\right),\left(\begin{array}{l}
\bar{\Delta} K_{1} \\
\bar{\Delta} K_{i 1} \\
\bar{\Delta} K_{p 1}
\end{array}\right)= \\
\left(\begin{array}{c}
1.28 \\
-0.17 \\
14.00
\end{array}\right),\left(\begin{array}{l}
\bar{\Delta} K_{2} \\
\bar{\Delta} K_{i 2} \\
\bar{\Delta} K_{p 2}
\end{array}\right)=\left(\begin{array}{l}
-0.63 \\
-0.63 \\
-0.63
\end{array}\right),\left(\begin{array}{l}
\bar{\Delta} \bar{N}_{1} \\
\bar{\Delta} \bar{N}_{2} \\
\bar{\Delta} T_{h 1} \\
\bar{\Delta} T_{h 2}
\end{array}\right)=\left(\begin{array}{c}
0.60 \\
-0.58 \\
0 \\
0
\end{array}\right), \\
\left(\begin{array}{l}
\bar{\Delta} F_{i 1} \\
\bar{\Delta} F_{i 2} \\
\bar{\Delta} F_{p 1} \\
\bar{\Delta} F_{p 2}
\end{array}\right)=\left(\begin{array}{c}
0.88 \\
-0.63 \\
9.56 \\
-0.42
\end{array}\right),\left(\begin{array}{l}
\bar{\Delta} f_{i 1} \\
\bar{\Delta} f_{i 2} \\
\bar{\Delta} y_{p 1} \\
\bar{\Delta} y_{p 2}
\end{array}\right)=\left(\begin{array}{c}
0.28 \\
-0.05 \\
13.32 \\
-0.05
\end{array}\right), \\
\left(\begin{array}{l}
\bar{\Delta} w_{1} \\
\bar{\Delta} w_{2} \\
\bar{\Delta} R_{1} \\
\bar{\Delta} R_{2}
\end{array}\right)=\left(\begin{array}{c}
0.10 \\
-0.05 \\
0.70 \\
-0.63
\end{array}\right),\left(\begin{array}{l}
\bar{\Delta} c_{1} \\
\bar{\Delta} c_{2} \\
\bar{\Delta} l_{1} \\
\bar{\Delta} l_{2}
\end{array}\right)=\left(\begin{array}{c}
0.10 \\
-0.05 \\
-0.60 \\
0.59
\end{array}\right)
\end{gathered}
$$

We now increase the tax rate on region 1's wage from 0.04 to 0.05 . Different from the increase in the tax rate on output, the national output and the capital stock em- ployed by the country are reduced. The trade balance is improved and wealth is increased. As region 1's tax rate on the wage rate is increased, the expenditure on public good is increased and work time is reduced (given all the other conditions). The improved infrastructure makes the region more attractive. Although the population of region 1 is increased, its labor force

The region's population is increased and productivity per work hour is increased. Region 1's wage rate and consumption are increased in association of rise in land rent; region 2's wage rate and consumption are reduced in association of fall in land rent. As the tax rate on wage is increased, the national supply of labor is reduced. Although more people immigrate to more productive region, the national output is still reduced. Because the output and wage are reduced in region 2, the regional public service and per capita expenditure on public good are reduced.

$$
\begin{gathered}
\tau_{w 1}: 0.04 \Rightarrow 0.05, \bar{\Delta} F=-0.75, \bar{\Delta} K=-0.16, \\
\bar{\Delta} \bar{K}=0.89, \bar{\Delta} B=5.60, \bar{\Delta} \bar{k}_{1}=1.16, \bar{\Delta} \bar{k}_{2}=-0.18, \\
\left(\begin{array}{c}
\bar{\Delta} N_{1} \\
\bar{\Delta} N_{i 1} \\
\bar{\Delta} N_{p 1}
\end{array}\right)=\left(\begin{array}{c}
-0.20 \\
-0.80 \\
9.07
\end{array}\right),\left(\begin{array}{l}
\bar{\Delta} N_{2} \\
\bar{\Delta} N_{i 2} \\
\bar{\Delta} N_{p 2}
\end{array}\right)=\left(\begin{array}{l}
-2.02 \\
-2.02 \\
-2.02
\end{array}\right),\left(\begin{array}{l}
\bar{\Delta} K_{1} \\
\bar{\Delta} K_{i 1} \\
\bar{\Delta} K_{p 1}
\end{array}\right)= \\
\left(\begin{array}{c}
1.37 \\
0.35 \\
10.33
\end{array}\right),\left(\begin{array}{l}
\bar{\Delta} K_{2} \\
\bar{\Delta} K_{i 2} \\
\bar{\Delta} K_{p 2}
\end{array}\right)=\left(\begin{array}{l}
-2.20 \\
-2.20 \\
-2.20
\end{array}\right),\left(\begin{array}{l}
\bar{\Delta} \bar{N}_{1} \\
\bar{\Delta} \bar{N}_{2} \\
\bar{\Delta} T_{h 1} \\
\bar{\Delta} T_{h 2}
\end{array}\right)=\left(\begin{array}{c}
2.08 \\
-2.02 \\
1.05 \\
0
\end{array}\right), \\
\left(\begin{array}{l}
\bar{\Delta} F_{i 1} \\
\bar{\Delta} F_{i 2} \\
\bar{\Delta} F_{p 1} \\
\bar{\Delta} F_{p 2}
\end{array}\right)=\left(\begin{array}{c}
0.35 \\
-2.20 \\
6.63 \\
-1,47
\end{array}\right),\left(\begin{array}{l}
\bar{\Delta} f_{i 1} \\
\bar{\Delta} f_{i 2} \\
\bar{\Delta} y_{p 1} \\
\bar{\Delta} y_{p 2}
\end{array}\right)=\left(\begin{array}{c}
-1.69 \\
-0.18 \\
8.09 \\
-0.18
\end{array}\right), \\
\left(\begin{array}{l}
\bar{\Delta} w_{1} \\
\bar{\Delta} w_{2} \\
\bar{\Delta} R_{1} \\
\bar{\Delta} R_{2}
\end{array}\right)=\left(\begin{array}{c}
1.16 \\
-0.18 \\
2.89 \\
-2.20
\end{array}\right),\left(\begin{array}{l}
\bar{\Delta} c_{1} \\
\bar{\Delta} c_{2} \\
\bar{\Delta} l_{1} \\
\bar{\Delta} l_{2}
\end{array}\right)=\left(\begin{array}{c}
0.80 \\
-0.18 \\
-2.04 \\
2.07
\end{array}\right)
\end{gathered}
$$

We now study the impact of changes in the congestion parameter, $\theta_{c}$. We increase the parameter value from 0.05 to 0.06 . The effects are listed in (32). The time distribution is not affected. As the congestion effect of public goods becomes stronger, most of the economic variables are negatively affected. It should be noted that although region 1's population is increased, the region's total capital and output are reduced. The economic loss caused by the strengthened congestion dominates the economic gain brought about by the labor increase. 
$\theta_{c}: 0.05 \Rightarrow 0.06, \bar{\Delta} F=-3.41, \bar{\Delta} K=-3.40, \bar{\Delta} \bar{K}=$ $-3.41, \bar{\Delta} B=-3.43, \bar{\Delta} \bar{k}_{1}=-3.23, \bar{\Delta} \bar{k}_{2}=-3.71$,

$$
\begin{aligned}
& \left(\begin{array}{l}
\bar{\Delta} N_{1} \\
\bar{\Delta} N_{i 1} \\
\bar{\Delta} N_{p 1}
\end{array}\right)=\left(\begin{array}{l}
0.23 \\
0.23 \\
0.23
\end{array}\right),\left(\begin{array}{l}
\bar{\Delta} N_{2} \\
\bar{\Delta} N_{i 2} \\
\bar{\Delta} N_{p 2}
\end{array}\right)=\left(\begin{array}{l}
-0.22 \\
-0.22 \\
-0.22
\end{array}\right),\left(\begin{array}{l}
\bar{\Delta} K_{1} \\
\bar{\Delta} K_{i 1} \\
\bar{\Delta} K_{p 1}
\end{array}\right)= \\
& \left(\begin{array}{l}
-3.01 \\
-3.01 \\
-3.01
\end{array}\right),\left(\begin{array}{c}
\bar{\Delta} K_{2} \\
\bar{\Delta} K_{i 2} \\
\bar{\Delta} K_{p 2}
\end{array}\right)=\left(\begin{array}{l}
-3.92 \\
-3.92 \\
-3.92
\end{array}\right),\left(\begin{array}{l}
\bar{\Delta} \bar{N}_{1} \\
\bar{\Delta} \bar{N}_{2} \\
\bar{\Delta} T_{h 1} \\
\bar{\Delta} T_{h 2}
\end{array}\right)=\left(\begin{array}{c}
0.23 \\
-0.22 \\
0 \\
0
\end{array}\right),
\end{aligned}
$$

$$
\begin{gathered}
\left(\begin{array}{l}
\bar{\Delta} F_{i 1} \\
\bar{\Delta} F_{i 2} \\
\bar{\Delta} F_{p 1} \\
\bar{\Delta} F_{p 2}
\end{array}\right)=\left(\begin{array}{l}
-3.01 \\
-3.92 \\
-0.82 \\
-1.28
\end{array}\right),\left(\begin{array}{l}
\bar{\Delta} f_{i 1} \\
\bar{\Delta} f_{i 2} \\
\bar{\Delta} y_{p 1} \\
\bar{\Delta} y_{p 2}
\end{array}\right)=\left(\begin{array}{c}
-3.23 \\
-3.71 \\
-3.3 \\
-3.71
\end{array}\right), \\
\left(\begin{array}{l}
\bar{\Delta} w_{1} \\
\bar{\Delta} w_{2} \\
\bar{\Delta} R_{1} \\
\bar{\Delta} R_{2}
\end{array}\right)=\left(\begin{array}{l}
-3.23 \\
-3.71 \\
-3.01 \\
-3.92
\end{array}\right),\left(\begin{array}{l}
\bar{\Delta} c_{1} \\
\bar{\Delta} c_{2} \\
\bar{\Delta} l_{1} \\
\bar{\Delta} l_{2}
\end{array}\right)=\left(\begin{array}{c}
-3.23 \\
-3.71 \\
-0.23 \\
0.22
\end{array}\right)
\end{gathered}
$$

We increase the externality parameter value, $\theta_{e}$, from 0.03 to 0.04 . The effects are listed in (33). As positive externalities become stronger, the industrial output, total capital employed by the economy, and the total wealth are increased. Region 1's population is increased. As region 2 loses labor and the time distribution is not affected, the region's output and capital stocks are reduced. Although region 1's output is increased, as its change rate is low, the net effect on the national industrial good falls. Also the labor of each sector in region 1 is increased. The wage rate, consumption level and wealth per capita in the two regions are all reduced. The lot size in region 1 is reduced and the region's housing rent is increased.

$$
\theta_{e}: 0.03 \Rightarrow 0.04, \bar{\Delta} F=-0.52, \bar{\Delta} K=-0.51, \bar{\Delta} \bar{K}=
$$$$
-0.52, \bar{\Delta} B=-0.57, \bar{\Delta} \bar{k}_{1}=-0.18, \bar{\Delta} \bar{k}_{2}=-1.14 \text {, }
$$

$$
\begin{aligned}
& \left(\begin{array}{c}
\bar{\Delta} N_{1} \\
\bar{\Delta} N_{i 1} \\
\bar{\Delta} N_{p 1}
\end{array}\right)=\left(\begin{array}{c}
0.50 \\
0.50 \\
0.50
\end{array}\right),\left(\begin{array}{l}
\bar{\Delta} N_{2} \\
\bar{\Delta} N_{i 2} \\
\bar{\Delta} N_{p 2}
\end{array}\right)=\left(\begin{array}{l}
-0.49 \\
-0.49 \\
-0.49
\end{array}\right),\left(\begin{array}{c}
\bar{\Delta} K_{1} \\
\bar{\Delta} K_{i 1} \\
\bar{\Delta} K_{p 1}
\end{array}\right)= \\
& \left(\begin{array}{l}
0.33 \\
0.33 \\
0.33
\end{array}\right),\left(\begin{array}{l}
\bar{\Delta} K_{2} \\
\bar{\Delta} K_{i 2} \\
\bar{\Delta} K_{p 2}
\end{array}\right)=\left(\begin{array}{l}
-1.62 \\
-1.62 \\
-1.62
\end{array}\right),\left(\begin{array}{c}
\bar{\Delta} \bar{N}_{1} \\
\bar{\Delta} \bar{N}_{2} \\
\bar{\Delta} T_{h 1} \\
\bar{\Delta} T_{h 2}
\end{array}\right)=\left(\begin{array}{c}
0.50 \\
-0.49 \\
0 \\
0
\end{array}\right),
\end{aligned}
$$

$$
\begin{gathered}
\left(\begin{array}{l}
\bar{\Delta} F_{i 1} \\
\bar{\Delta} F_{i 2} \\
\bar{\Delta} F_{p 1} \\
\bar{\Delta} F_{p 2}
\end{array}\right)=\left(\begin{array}{c}
0.33 \\
-1.62 \\
0.30 \\
-0.68
\end{array}\right),\left(\begin{array}{l}
\bar{\Delta} f_{i 1} \\
\bar{\Delta} f_{i 2} \\
\bar{\Delta} y_{p 1} \\
\bar{\Delta} y_{p 2}
\end{array}\right)=\left(\begin{array}{l}
-0.18 \\
-1.14 \\
-0.18 \\
-1.14
\end{array}\right), \\
\left(\begin{array}{l}
\bar{\Delta} w_{1} \\
\bar{\Delta} w_{2} \\
\bar{\Delta} R_{1} \\
\bar{\Delta} R_{2}
\end{array}\right)=\left(\begin{array}{c}
-0.18 \\
-1.14 \\
0.33 \\
-1.62
\end{array}\right),\left(\begin{array}{l}
\bar{\Delta} c_{1} \\
\bar{\Delta} c_{2} \\
\bar{\Delta} l_{1} \\
\bar{\Delta} l_{2}
\end{array}\right)=\left(\begin{array}{c}
-0.18 \\
-1.14 \\
-0.50 \\
0.49
\end{array}\right)
\end{gathered}
$$

\section{Conclusions}

This paper proposed a two-region growth model with capital accumulation, amenity and regional public goods under assumptions of profit maximization, utility maximization, and perfect competition. We emphasize effects of congestion and various fiscal policies on long-term economic growth and economic geography. As the model is structurally general, it is possible to deal with various national as well as regional issues. Given the contemporary literature on (spaceless) economic growth, we may extend and generalize the model in different ways. We may analyze behavior of the model with other forms of production or utility functions. Other important extensions include incorporating transportation costs and endogenous population growth into the model. We may also refine our model by dividing public expenditures on capital into maintenance and new investment. As empirically demonstrated in [14,15], maintenance expenditures on public capital can account to 2 to 3 percent of GDP in some economies like USA and Canada. As in [16] in which the composition of public capital expenditures under congestion is an important factor for optimal fiscal policies, we may consider possible effects of public maintenance expenditures on the depreciation of public capital.

\section{Acknowledgements}

The author is grateful to an anonymous referee for the constructive comments. Financial support under "the Grant-in-Aid for Scientific Research (C), Project No.: 21530246, Japan Society for the Promotion of Science” and "APU Academic Research Subsidy", is gratefully acknowledged. The usual disclaimer applies.

\section{References}

[1] W. B. Zhang, "Economic Growth Theory. Hampshire: Ashgate,” 2005. 
[2] W. B. Zhang, "International Trade Theory: Capital, Knowledge, Economic Structure, Money and Prices over Time and Space,” Springer, Berlin, 2008.

[3] W. B. Zhang, "A Multi-Region Model with Capital Accumulation and Endogenous Amenities," Environment and Planning A, Vol. 39, No. 9, 2007, pp. 2248-2270.

[4] H. Oniki and H. Uzawa, "Patterns of Trade and Investment in a Dynamic Model of International Trade," Review of Economic Studies, Vol. 32, 1965, pp. 15-38.

[5] A. V. Deardorff, "The Gains from Trade in and out of Steady State Growth,” Oxford Economic Papers, Vol. 25, No. 2, 1973, pp. 173-191.

[6] R. J. Ruffin, "Growth and the Long-Run Theory of International Capital Movements," American Economic Review, Vol. 69, No. 5, 1979, pp. 832-842.

[7] R. Findlay, "Growth and Development in Trade Models," In: R. W. Jones and R. B. Kenen, Eds., Handbook of International Economics, Amsterdam, North-Holland, 1984.

[8] J. Eaton, “A Dynamic Specific-Factors Model of International Trade," Review of Economic Studies, Vol. 54, No. 2, 1987, pp. 325-338.

[9] R. A. Brecher, Z. Q. Chen and E. U. Choudhri, “Absolute and Comparative Advantage, Reconsidered: the Pattern of International Trade with Optimal Saving," Review of
International Economics, Vol. 10, No. 4, 2002, pp. 645656.

[10] G. Sorger, "On the Multi-Country Version of the Solow-Swan Model,” The Japanese Economic Review, Vol. 54, No. 2, 2002, pp. 146-164.

[11] T. Eicher and S. Turnovsky, "Scale, Congestion and Growth,” Economica, Vol. 67, No. 267, 2000, pp. 325346.

[12] M. A. Gómez, "Fiscal Policy, Congestion, and Endogenous Growth,” Journal of Public Economic Theory, Vol. 10, No. 4, 2008, pp. 595-622.

[13] A. B. Abel and B. S. Bernanke, "Macroeconomics," 3rd Edition, Addison-Wesley, New York, 1998.

[14] E. McGrattan and J. Schmitz, "Maintenance and Repair: Too Big to Ignore," Federal Reserve Bank of Minneapolis Quarterly Review, Vol. 23, No. 4, 1999, pp. 2-13.

[15] P. Kalaitzidakis and S. Kalyvitis, "Financing 'New' Public Investment and/or Maintenance in Public Capital for Growth? The Canadian Experience,” Economic Inquiry, Vol. 43, 2005, pp. 586-600.

[16] E. V. Dioikitopoulos and S. Kalyvitis, "Public capital Maintenance and Congestion: Long-Run Growth and Fiscal Policies," Journal of Economic Dynamics \& Control, Vol. 32, No. 12, 2008, pp. 3760-3779. 